\title{
О перспективах использования апатита из щелочно-ультраосновных и карбонатитовых интрузий Кольского полуострова для термохронологических расчетов
}

\section{Ганнибал М.А., Каменский И.Л., Каулина Т.В.}

Геологический институт КНЦ РАН, Anamumы, m.a.gannibal@gmail.com

Аннотация. В статье представлены результаты предварительного исследования U-Th-Не системы в образце апатита из Ковдорского массива. Обсуждается потенциальная пригодность подобных исследований для изучения термической истории пород массива.

Ключевые слова: уран, торий гелий, U-Th-Не система, термохронология, возраст, апатит.

\section{Prospects of using apatite from alkaline-ultrabasic and carbonatite intrusions of the Kola Peninsula for thermochronological studies}

\author{
Hannibal M.A., Kamensky I.L., Kaulina T.V. \\ Geological Institute KSC RAS, Apatity, m.a.gannibal@gmail.com
}

Abstract. The article presents the preliminary results of a study of the U-Th-He system in a sample of apatite from the Kovdor massif. The potential usefulness of such studies for learning early thermal history of rocks of the massif is discussed.

Keywords: uranium, thorium, helium, U-Th-He system, thermochronology, age, apatite.

В связи с аномально высокой подвижностью гелия в силикатах U-Th-Hе система используется, главным образом, для оценки сохранности гелия путем сопоставления его измеренных концентраций с рассчитанными в рамках изотопно-геохимических реконструкций (см. например, (Tolstikhin et al., 2016)). Для датирования эта система применяется довольно ограниченно и, в основном, в термохронологии. Минералы, в которых U-Th-Не система используется в качестве геотермометра, должны удовлетворять некоторым требованиям, в частности: содержать достаточное количество родительских элементов (U и Th) для генерации измеримых концентраций гелия в течение датируемого возрастного интервала, а также количественно удерживать гелий. Вклад захваченного гелия должен быть либо минимальным, либо легко идентифицироваться по изотопному составу. Соответствие этим условиям носит скорее индивидуальный характер, однако есть некоторые закономерности, характерные для минеральных видов в целом. Так, известно, что кварц не сохраняет гелий даже при крайне низких температурах; многие породообразующие минералы не имеют в составе катионов, способных изоморфно замещаться U и Th.

Апатит в этом отношении считается перспективным. Его применение для решения задач термохронологии обусловлено следующими факторами: (i) относительно высокое содержание урана в этом минерале, связанное с изоморфным замещением ионов кальция; (ii) хорошая сохранность гелия при температурах, не превышающих температуры закрытия U-Th-Не изотопной системы; (iii) широкое распространение в разных типах пород. Температура закрытия U-Th-Не системы в апатите по разным оценкам (и для разных минеральных индивидов) составляет от 68 до $100^{\circ} \mathrm{C}$. Подробные исследования U-Th-Не системы в апатитах изложены, в частности, в работах (Lippolt et al., 1994; Farley, 2000).

Цель настоящей работы - выявить потенциальную пригодность апатита девонских интрузий Кольского полуострова для термохронологических исследований. Для этого была изучена U-ThНе система в образце апатита из мелилит-оливин-кальцитового пегматита из Ковдорского массива. Ковдорский массив (рис. 1) размером $5.5 \times 8$ км расположен в юго-западной части Кольского полуострова среди гнейсов Беломорского террейна (Кухаренко и др., 1965) и представляет собой крупную интрузию центрального типа, имеющую концентрически зональное строение. Его центральное ядро сложено оливинитами, которые окружены оливин-клинопироксеновыми, флогопит- 


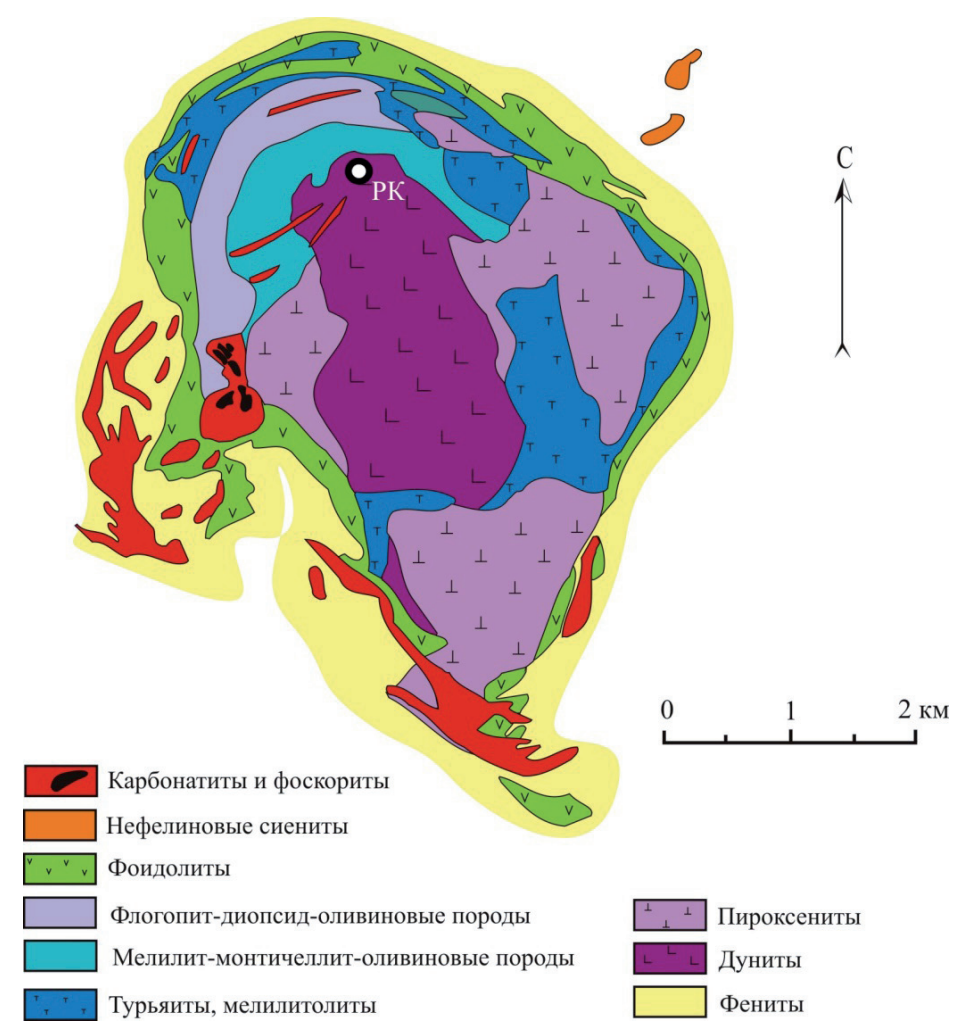

Рис. 1. Место отбора пробы (РК) на схеме геологического строения Ковдорского массива (Арзамасцев и др., 2009).

Fig.1. Sampling site on a geological map of the Kovdor massif (Arzamastsev et al., 2009).

клинопироксеновыми и клинопироксеновыми породами, включая гигантские пегматитовые тела с кристаллами оливина, клинопироксена и флогопита метровых размеров. Периферийная часть комплекса состоит из ранних мелилитсодержащих и ийолит-мельтейгитовых и поздних ийолитуртитовых пород.

$\mathrm{Rb}-\mathrm{Sr}$ возраст ультраосновных пород массива составляет от $373 \pm 5$ до $376 \pm 1$ млн. лет (Zaitsev and Bell, 1995). Возраст карбонатитов и фоскоритов определен U-Pb методом по бадделеиту в $378.5 \pm 0.3$ млн. лет (Amelin and Zaitsev, 1997) и $382 \pm 3$ млн. лет (Баянова и др., 1997).

Расположение мелилит-оливин-кальцитовых пегматитов, из которых была отобрана проба, отмечено на рисунке 1.

В рамках настоящего исследования был определен U-Pb возраст апатита по отношению ${ }^{206} \mathrm{~Pb} /{ }^{238} \mathrm{U}$, концентрации урана и тория, а также концентрации и изотопному составу гелия.

Для извлечения гелия из образцов использовались две методики: дробление в вакуумированных стеклянных ампулах, при котором высвобождается гелий флюидных микровключений, и плавление, при котором выделяется весь гелий образца. Навески минералов были представлены частицами, размером 0.25-0.63 мм. Строго говоря, температура прогрева образца не обеспечивала его плавления. Однако низкая температура закрытия апатита для гелия позволяет обоснованно предположить, что при прогреве гелий был выделен полностью.

Результаты измерения концентраций изотопов гелия представлены в таблице 1 . Анализируя распределение изотопов гелия в апатите, можно заметить, что при дроблении выделяется лишь небольшая часть ( 5 \%) гелия, причем гелий, освобожденный из микровключений (дробление) имеет заметно более высокое значение ${ }^{3} \mathrm{He} /{ }^{4} \mathrm{He}$, чем валовый гелий образца.

Учитывая однозначно мантийное происхождение Ковдорского массива, избыток легкого изотопа во фракции гелия, выделенной дроблением, следует приписать присутствию во включениях ювенильной компоненты гелия с высоким отношением ${ }^{3} \mathrm{He} /{ }^{4} \mathrm{He}$, существенно «разбавленной» радиогенным гелием. Высокое содержание гелия в апатите связано с высокими содержаниями урана, из- 
меренными в двух навесках апатита (17.3 и 18.9 г/т) и, в особенности, тория (1235 и 1228 г/т), при распаде которых образуется ${ }^{4} \mathrm{He}$.

Таблица 1. Результаты изотопных анализов гелия в образце апатита (РК).

Table 1. Helium concentrations and isotopic composition in the apatite sample (PK).

\begin{tabular}{|c|c|c|c|c|}
\hline Навеска, г & $\begin{array}{c}{ }^{4} \mathrm{He} * 10^{-6}, \\
\mathrm{~cm}^{3} / \Gamma\end{array}$ & $\left({ }^{3} \mathrm{He} /{ }^{4} \mathrm{He}\right) * 10^{-8}$ & $\begin{array}{c}{ }^{3} \mathrm{He} * 10^{-10}, \\
\mathrm{~cm}^{3} / \Gamma\end{array}$ & $\begin{array}{c}\text { Метод } \\
\text { экстракции }\end{array}$ \\
\hline 1.0 & 450 & 63 & 2.835 & дробление \\
\hline 0.065 & 12243 & 10 & 12.243 & прогрев \\
\hline 0.091 & 11751 & 2.5 & 2.938 & прогрев \\
\hline 0.50 & 518 & 52 & 2.694 & дробление \\
\hline 0.50 & 597 & 49 & 2.925 & дробление \\
\hline
\end{tabular}

Возраст апатита из мелилит-оливин-кальцитового пегматита, определенный U-Pb методом по отношению ${ }^{206} \mathrm{~Pb} /{ }^{238} \mathrm{U}$ составляет 374 и 410 млн. лет для двух навесок, соответственно. Такой разброс, а также большая ошибка датировок связаны с тем, что возраст породы в сочетании с концентрацией урана в образцах апатита не обеспечивают достаточных концентраций радиогенного свинца.

U-Th-Не возраст апатита, рассчитанный на основании представленных выше данных о валовых содержаниях гелия, урана и тория составляет в среднем (для двух анализов Не и двух U и Th) $317 \pm 9$ млн. лет, что говорит о сравнительно небольших, учитывая высокую подвижность гелия, потерях ${ }^{4} \mathrm{He}(15-18 \%)$ из структуры апатита.

Если в самом грубом приближении принять, что переход U-Th-Не системы из «закрытого» состояния в «открытое» был скачкообразным, получается, что породы интрузии миновали температуру закрытия около 50-70 млн. после образования. Для построения более или менее надёжной модели нужны дополнительные данные, в частности, параметры диффузии гелия, характерные именно для этой разновидности апатита. Полезно также было бы исследовать коллекцию образцов, отобранных из разных фаз интрузии и сопоставить полученные результаты. Тем не менее, учитывая хорошую сохранность радиогенного гелия и относительно равномерное его распределение, уже на данном этапе можно сказать, что исследованные образцы апатита пригодны для термохронологических исследований и могут пролить свет на раннюю термическую историю интрузии.

Исследования выполнены в рамках Госзадания ГИ КНЦ РАН, тема НИР 0226-2019-0052

\section{Литература}

1. Арзамасцев А.А., Федотов Ж.А., Арзамасцева Л.В. Дайковый магматизм северо-восточной части Балтийского щита. СПб.: Наука. 2009. 383 с.

2. Баянова Т.Б., Кирнарский Ю.М., Левкович Н.В. U-Pb датирование бадцелеита из пород Ковдорского массива // ДАН. 1997. Т. 356. N 4. С. 509-511.

3. Кухаренко А.А., Орлова М.П., Булах А.Г., Багдасаров Э.А., Римская-Корсакова О.М., Нефедов Е.И., Ильинский Г.А., Сергеев А.С., Абакумова Н.Б. Каледонский комплекс ультраосновных, щелочных пород и карбонатитов Кольского полуострова и Северной Карелии (Геология, петрология, минералогия и геохимия). 1965. Москва: Недра. 772 с.

4. Amelin Y.V. and Zaitsev A.A precize U-Th-Pb chronology of carbonatites and phoscorites: problems related to extreme elemental fractionation, and possible solution using multi-mineral approach // GAC/MAC Annual Meeting. 1997. P. A-2.

5. Farley K. A. Helium diffusion from apatite' General behavior as illustrated by Durango fiuorapatite // J. Geophys. Res. 2000. V. 105. N. B2. P. 2903-2914.

6. Lippolt H.J., Leitz M., Wernicke R.S., and Hagedorn B. (Uranium + thorium )/helium dating of apatite: experience with samples from different geochemical environments // Chemical Geology (Isotope Geoscience Section). 1994. V. 112. P. 179-191.

7. Tolstikhin I.N., Verchovsky A.B., Kamensky I.L., Skiba V.I. Gannibal M.A., Vetrin V.R., Tarakanov S.V. Amphibole: a major carrier of helium isotopes in crustal rocks // Chemical Geology. 2016. V. 444. P. 187-198.

8. Zaitsev A. N. and Bell K. Sr and Nd isotope data of apatite, calcite and dolomite as indicators of source and the relationships of phoscorites and carbonatites from the Kovdor massif, Kola Peninsular, Russia // Contrib. Miner. Petrol. 1995. V. 121. P. 324-335. 